\title{
Erratum to: Cost-Utility Analysis of Deferiprone for the Treatment of $\beta$-Thalassaemia Patients with Chronic Iron Overload: A UK Perspective
}

\author{
Anthony Bentley $\cdot$ Samantha Gillard • \\ Michael Spino $\cdot$ John Connelly $\cdot$ Fernando Tricta
}

Published online: 5 November 2013

(C) Springer International Publishing Switzerland 2013

Erratum to: PharmacoEconomics (2013) 31:807-822

DOI 10.1007/s40273-013-0076-z

After publication it was identified by the authors that they had supplied the incorrect figure files for Fig. 2a-c (located on p. 817). Attached to this erratum are the correct files. In addition, there is some additional text to the legend of Fig. 2 to be added to the end of the current legend:

*Values truncated for display purposes.
The online version of the original article can be found under doi:10. 1007/s40273-013-0076-z.

\section{A. Bentley $(\bowtie) \cdot$ S. Gillard}

Abacus International, 6 Talisman Business Centre,

Talisman Road, Bicester, Oxfordshire OX26 6HR, UK

e-mail: abentley@abacusint.com;

anthony.bentley@abacusint.com

M. Spino $\cdot$ J. Connelly $\cdot$ F. Tricta

ApoPharma Inc., 200 Barmac Drive, Toronto M9L 227, Canada

\section{Spino}

Leslie Dan Faculty of Pharmacy, University of Toronto,

Toronto, Canada
Fig. 2 Tornado diagrams for the sensitivity analyses of DFP vs a DFX, b DFO, and c combination therapy. $B I$ balloon infuser, $D F O$ desferrioxamine, $D F P$ deferiprone, $D F X$ deferasirox, $N Y H A$ New York Heart Association, $T x$ treatment. *Values truncated for display purposes 
(a) Cardiac mortality at Yr5: DFX

(1.58\% to $9.71 \%$; base case $4.84 \%)$

DFX: Daily dose

(50.00 to 10.00 ; base case 30.00 )

Cardiac mortality at Yr5: DFP

(2.49\% to $0.00 \%$; base case $0.00 \%$ )

Utility: NYHA I

(1.00 to 0.82 ; base case 0.92 )

Utility: Route of administration - Oral

(0.66 to 1.00 ; base case 0.84 )

DFX: Tx per annum

(365.00 to 273.75 ; base case 365.00 )

$\%$ of pts with cardiac disease: DFX

( $11.78 \%$ to $30.22 \%$; base case $21.00 \%$ )

DFP: Daily dose

(50.00 to 100.00 ; base case 75.00 )

Estimated average weight

(68.00 to 58.00 ; base case 63.00 )

Rate of adverse event - Hepatitis: DFX $(0.02 \%$ to $1.58 \%$; base case $0.70 \%)$

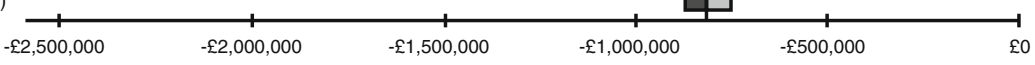

(b) Utility: Route of administration - Oral (0.66 to 1.00 ; base case 0.84 )

Utility: Route of administration - Infusion ( 0.84 to 0.25 ; base case 0.66 )

Generic DFO: Tx per annum

(325.00 to 195.00; base case 260.00)

Unit cost: Balloon infuser

(£43 to £26; base case £35)

Generic DFO: Daily dose

( 50.00 to 20.00; base case 40.00 )

DFP: Daily dose

(50.00 to 100.00 ; base case 75.00 )

$\%$ of pts: Balloon infuser - $100 \%$ B

(100.00\% to $75.00 \%$; base case $100.00 \%$ )

Cardiac mortality at Yr5: DFO

(1.58\% to $9.71 \%$; base case $4.84 \%$ )

DFP: Tx per annum

(273.75 to 365.00 ; base case 365.00 )

Monitoring costs: Neutrophil count

(£2.61 to £15.50; base case £3.47)

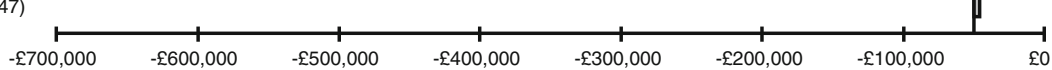

(C) Utility: Route of administration - Infusion ( 0.84 to 0.25 ; base case 0.66 )

Utility: Route of administration - Oral ( 0.66 to 1.00 ; base case 0.84 )

Combo: Generic DFO - Tx per annum (365.00 to 156.00; base case 208.00)

Combo: DFP - Daily dose

(100.00 to 10.00 ; base case 75.00 )

DFP: Daily dose

(50.00 to 100.00; base case 75.00 )

Unit cost: Balloon infuser

(£43 to £26; base case £35)

Combo: Generic DFO - Daily dose

(50.00 to 20.00; base case 40.00)

Cardiac mortality at Yr5: DFP \& DFO combination

$(0.00 \%$ to $2.49 \%$; base case $0.00 \%$ )

Combo: DFP - Tx per annum

(365.00 to 273.75; base case 365.00 )

DFP: Tx per annum

(273.75 to 365.00 ; base case 365.00 )

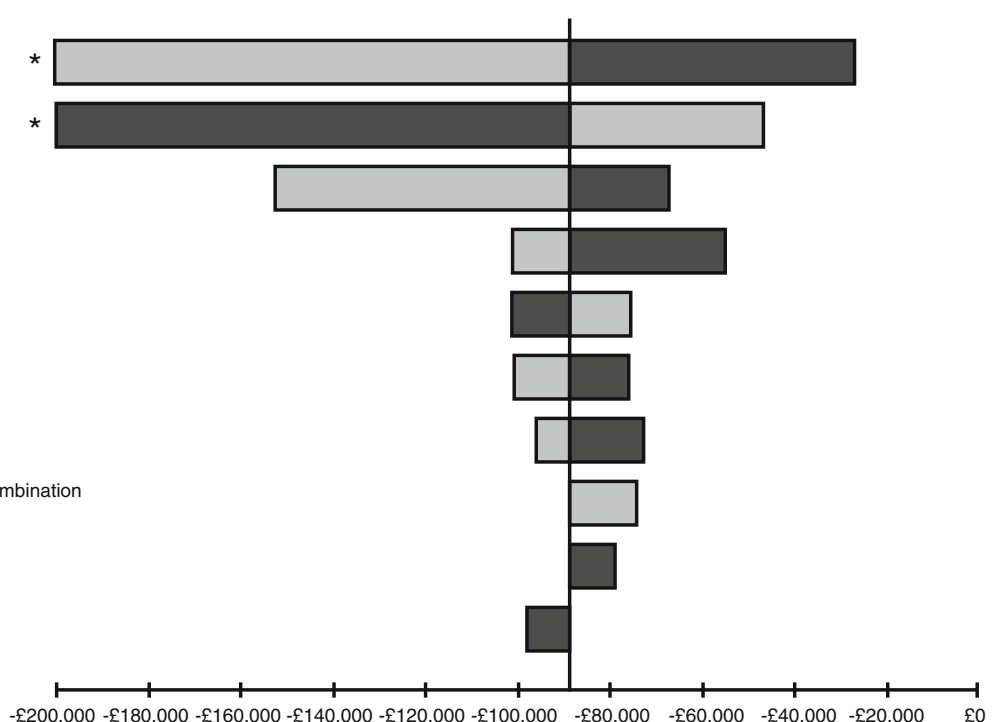

